\title{
Modeling the Ferrite-to-Austenite Transformation in the Heat-Affected Zone of Stainless Steel Multi-pass Welds
}

\author{
J. M. Vitek, S. A. Vitek, and S. A. David \\ Oak Ridge National Laboratory \\ Oak Ridge, Tennessee 37831-6376 \\ U.S. A.
}

MECENIEO

FEB 051986

OSTI

\section{4th International Conference on Trends in Welding Research Gatlinburg, Tennessee, June 5-8, 1995}

\section{DISCLAIMER}

\begin{abstract}
This report was prepared as an account of work sponsored by an agency of the United States Government. Neither the United States Government nor any agency thereof, nor any of their employees, makes any warranty, express or implied, or assumes any legal liability or responsibility for the accuracy, completeness, or usefulness of any information, apparatus, product, or process disclosed, or represents that its use would not infringe privately owned rights. Reference herein to any specific commercial product, process, or service by trade name, trademark, manufacturer, or otherwise does not necessarily constitute or imply its endorsement, recommendation, or favoring by the United States Government or any agency thereof. The views and opinions of authors expressed herein do not necessarily state or reflect those of the United States Government or any agency thereof.
\end{abstract}

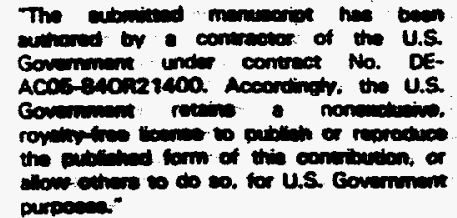




\begin{abstract}
The ferrite/austenite transformation in austenitic stainless steel welds was modeled by considering the transformation as a diffusion-controlled process. A finite-difference method was used to solve the diffision equations. The transformation behavior was evahuated for both isothermal aging and linear cooling over a range of cooling rates. The analysis provides information on the change in ferrite content as a function of heat treatment as well as the rate of the formation (or dissolution) of ferrite. The cormpositions of the ferrite and austenite are also obtained in the analysis. The reselts show that the approach to equilibrium can often be indirect and sometimes counter to intuition. The analysis is useful in providing information on the microstructural stability in austenitic stainless steel welds that cannot be obtained experimentally.
\end{abstract}

KNOWLEDGE OF THE MATERIAL MICROSTRUCTURE is critical in order to understand and project how a material will respond to further processing and to service conditions. The microstructure controls the properties such as strength, corrosion resistance, toughmess, ductility, and weldability. In addition, a thorough understanding of the microstructure is important in evaluating the alloy stability when exposed to elevated temperatures during service. This is particulariy important in welding where the heat-affected zone (HAZ) may be subjected to temperetures up to the solidus tempersture. Finally, in the case of welds, the microstructure in the HAZ may be very important becmese this region acts as the "mold" for solidification of the weld. Due to the epitaxial nature of solidification during welding, the microstructure of the HAZ at the time of solidification may have a significant influence on the solidification process and the final weld microstructure.

There are several means by which the microstructure can be assessed. Direct observation is the most straightforward approach, but it is limited by the extent to which the microstructures and phases present in the HAZ at elevated temperatures can be preserved at the observation temperature. Equilibrium phase diagrams can also provide much guidance in evaluating the microstructure. In the case of weldments, constitution diagrams such as the Schaeffler diagram (1) and recent revisions (2) provide additional information on the weld microstructure. However, these diagrams also have limitations. Equilibrium diagrams are of limited value because equilibrium is often not achieved under normal welding conditions. Constitution diagrams cover a wide range of alloy compositions by invoking nickel and chromium equivalents. As such, they are-a very valuable first approximation, but they may be of limited accuracy for specific ailoys since they represent average behavior. In addition, constitution diagrams do not consider all variables that may have an influence on the microstructure, such as cooling rate, and therefore their predictions may not be accurate under certain conditions (3).

For welding conditions, the material in the $\mathrm{HAZ}$ is subjected to very high temperatures. At these temperatures, experimental evaluation of the phase stability and transformation behavior is extremely difficuit, if not impossible. In addition, experimental studies are alloy specific and therefore cannot be automatically expanded to other alloy compositions. Because of these limitations, modeling of the microstructural development is advantageous and desirable... Modeling can be readily applied to different compositions, and can provide critical information on the high-temperature phase stability that cannot be easily obtained otherwise. Modeling can also provide a wide variety of information, such as phase compositions, kineties of the transformation, the influence of changing temperature cycles, and so on.

For austenitic stainless steel welds, the microstructure typically consists of two phases: an austenitic matrix phase $(\gamma)$ with residual ferrite $(\alpha)$. Figure I shows a typical fusion zone (FZ) microstructure, with a ferrite content of approximately $10 \%$. When exposed to elevated ternperatures, either during subsequent welding passes or in service, the microstructure is not stable. Depending upon the exact thermal conditions, the ferrite may grow at high temperatures, or it may dissolve or transform at lower temperatures. Evidence of this phase instability is revealed in 


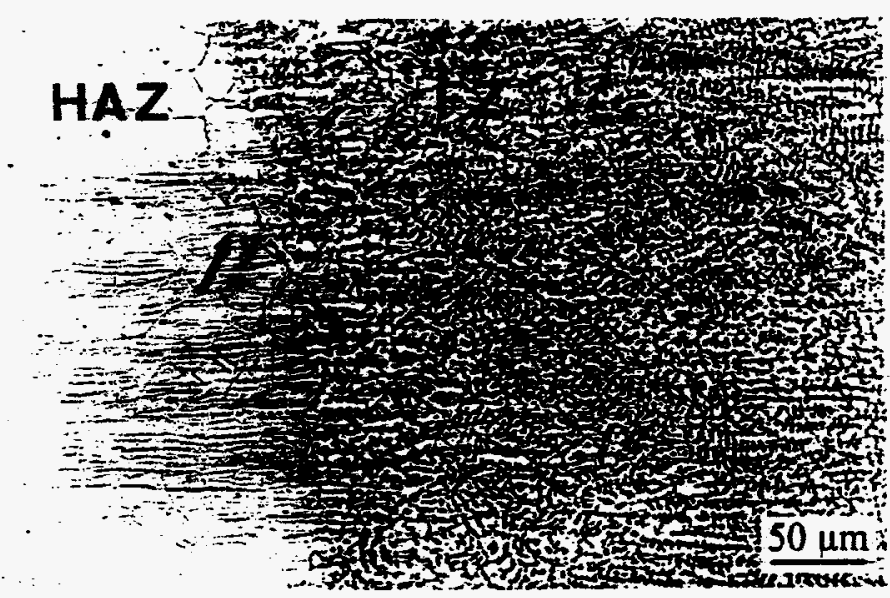

Fig. 1 - Typical austenite plus ferrite microstructure in an austenitic stainiess steel weld (type 304 S.S.).

Figure 1. The base material is fully austenitic, but in the HAZ, immediately adjacent to the $F Z$, some intergranuiar ferrite can be found, as indicated by the arrow. This ferrite must have formed during the exposure of this region to elevated temperatures during the thermal cycie. Direct observation, as in Figure 1, reveais that ferrite formed, but it does not give any indication as to the extent of ferrite formation at elevated temperatures, prior to cooling, and the extent of the dissolution of ferrite during cooling. If the ferrite formetion is extensive at elevated temperatures, then its presence may have a profound effect on the solidification behavior. These issues cannot be readily resolved by direct observation, but modeling of the ferrite-austenite transformation can provide valuable insight into the rate and extent of the reaction at the elevated temperatures. In the present study, the ferrite-austenite transformation has been modeled by evaluating it as a diffusioncontrolled transformation. Information such as the extent of ferrite formation, the ferrite composition, and the influence of cooling rate on these quantities can be readily provided by such a modeling approach.

\section{Calculation Procedure}

The model was based on the evaluation of the diffusioncontrolled growth or dissolution of ferrite in an austenitic matrix. Nucleation of ferrite was not considered since the starting microstructure contained both phases. Figure $2(a)$ illustrates the geometry of the system that was modeled, and Figure $2(b)$ shows how this model system can be used to represent a standard volume element in the actual microstructure. Referring to Figure 2(a), a one-dimensional system of finite size $L$ was considered, with a planar interface between the ferrite (size l) and austenite (size Ll). In weldments, the ferrite exists at the dendrite cores, and it would be more realistic to assume a cylindrical geometry for the ferrite. However, it has been shown (4) that there is basically no difference in the kinetics of the transformation for planar, cylindrical, or spherical geometries as long as the ferrite is centered at the core of the system, as is appropriate for the modeling of austenitic stainiess steels.

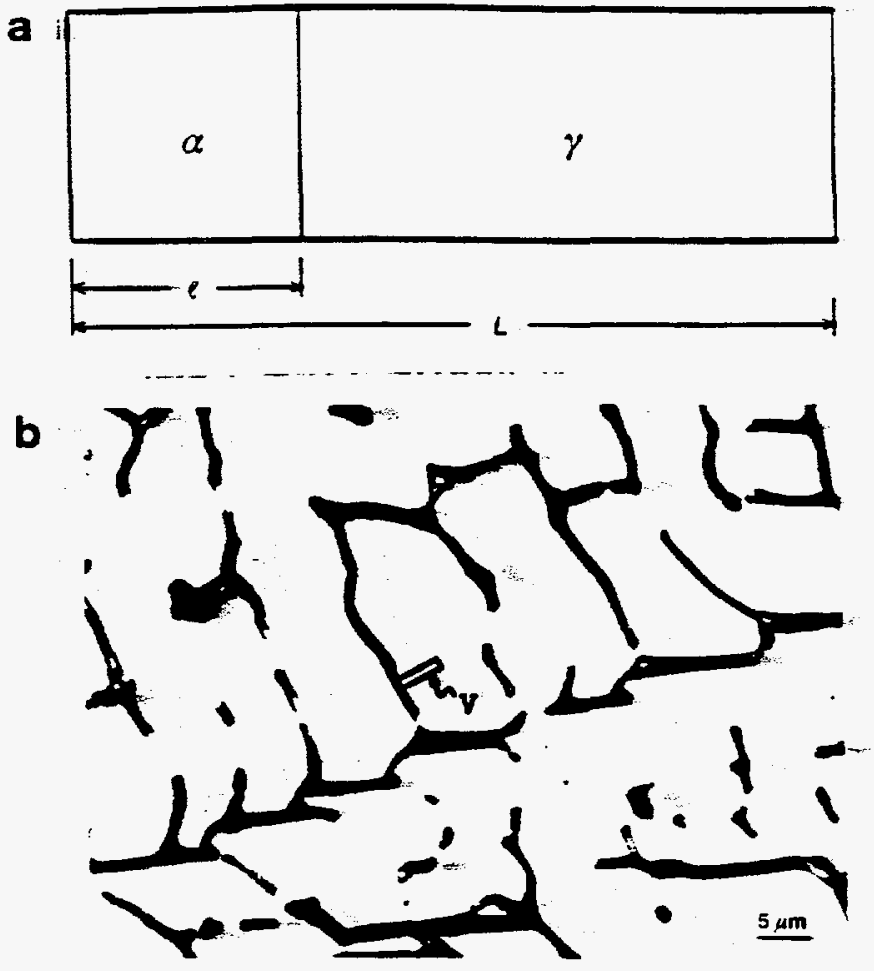

Fig. 2 - (a) Schematic of modeled system and (b) volume element, $V$, that can be used to model the entire microstructure.

For simplicity, the initial ferrite and austenite compositions were assumed to be constant (but different). Commercial stainless steel alloy compositions were modeled by considering an $\mathrm{Fe}-\mathrm{Cr}-\mathrm{Ni}$ ternary alloy. As will be shown, the use of ternary alloys leads to many interesting resuits that are typical of multicomponent systems in general, and these effects would not be observed if only a binary system was considered. This is because in binary systems, there is one tie-line in a two-phase field at each temperature. However, in temary and higher order systems, the added degree of freedom allows for a range of tielines between ferrite and austenite at one temperature, and this added flexibility permits for many new types of behavior.

The analysis involved the solution of Fick's Second Law, given as:

$$
\frac{\partial C}{\partial t}=D \frac{\partial^{2} C}{\partial x^{2}}
$$

where $C$ represents the composition, $t$ is the time, $D$ is the diffusion coefficient, and $x$ is the distance. At the interface between the ferrite and austenite phases, a mass balance is specified. This mass balance requires that the rate of growth of the ferrite is balanced by the net flux of chromium or nickel at the interface. Mathematically, this mass balance is given by:

$$
-D_{a} \frac{\partial C_{E}}{\partial x}+D_{Y} \frac{\partial C_{Y}}{\partial x}=\frac{\partial x}{\partial t}\left(C_{Y}-C_{\varepsilon}\right) \text {. }
$$

The subscripts $\alpha$ and $\gamma$ refer to the ferrite and austenite phases, respectively, and the concentration derivatives in the above 
equation are evaluded at the ferrite/austenite interface. This mass balance must be satisfied for both the chromium and nickel constiments. The equitibrium interface compositions (tie-line compositions) are adjusted so that the interface velocities determined from the nickel and chromium mass balances are equal. An improved iteration scheme was utilized so that the mass balances were satisfied with s consistent set of compositions (4).

The diffision equations were transformed into an implicit, finite-difference form following the approach described in the literature (5-7). The wse of a finite-difference approach was required because of the combination of a termary system, rather than a binary one, and the finite size of the total system. This latter condition allows for overispping profiles from neighboring volume elements [sec Figure 2(b)]. Without the finite size and the ternary system features, the diffirion equations could be solved by ansiytical mens A fixed mumber of nodes was specified for both the ferrite and-austenite phases The Murray-Landis transformation $(7,8)$ was used to account for the interface movement when specifying the positions of the nodes. A similar approach has been used recently by Kikuchi, Kajihara, and coworkers (9-11) to study the ferrite-austenite transformation in stainiess steet castings during isothermal aging at $1100^{\circ} \mathrm{C}$. The present study concentrates on austenitic stainless steel compositions that are typical of weiding alloys, and the calculations were carried out over a range of isothermal aging temperatures from 700 to $1300^{\circ} \mathrm{C}$. In addition, the present study inctudes calculations for non-isothermal conditions in which a range of constant cooling rates were considered.

In the curreoc analysis; the assumptions and simplifications included (1) composition-independent diffusion coeficients, (2) equal densities for ferrite and austenite (so that compositions could be expressed in weight percent), (3) crossterm diffusion coefficients were negligible, (4) the presence of sigma phase was ignored by not allowing it to form, and (5) equilibrium at the ferrite-eustenite interface. The diffusion coefficients were temperature dependent. The equilibrium at the interface between ferrite and austenite was specified by the ThermoCalc ${ }^{\text {TM }}$ program (12). The data from ThermoCalc provided the equiibrium ferrite and austenite compositions as a function of both temperware and overall alloy composition. These results were then incorporated into the finite-difference software code in an analytical form. The details of this procecture, and the actual analytical exprescions that were used, are given eisewhere (7). It was shown that this analytical representation of the phase boundaries and tie-lines was quite accurate over the temperature range considered in this study, namely 700 to $1300^{\circ} \mathrm{C}$. The mathematical expressions for the diffusion equations in finitedifferemee form, the diffiusion parameters, and the accuracy of the methodology are described in detail in another paper (7).

The present paper describes results for two alloy compositions that are representative of austenitic weld filler metal compositions (in wt \%): $\mathrm{Fe}-21.9 \mathrm{Cr}-10.35 \mathrm{Ni}$ and $\mathrm{Fe}-21 \mathrm{Cr}-11.3 \mathrm{Ni}$. The starting compositions of the ferrite and austerite were Fe$30 \mathrm{Cr}-4.5 \mathrm{Ni}$ and Fe-21Cr-11Ni, respectively, for the first alloy, and Fe-30Cr-5Ni and Fe-20Cr-12Ni, respectively, for the second alloy. These ferrite and austenite compositions are typical for these phases in the as-welded condition, as determined by analytical electron microscopy (13-15). The size of the system, $L$, was fixed at $5 \mu \mathrm{m}$ while the initial ferrite size was $0.5 \mu \mathrm{m}$ As can be seex in Figure 2(b), these sizes are appropriate for a representative sample volume in the as-welded condition. The calculations were carried out for isothermal aging at $100^{\circ}$ intervals from 700 to $1300^{\circ} \mathrm{C}$ until final equilibrium was reached at each temperature. Representative results for 1000 and $1200^{\circ} \mathrm{C}$ aging will be presented beres, results for other temperatures may be found elsewhere (7). Calculations were also made for non-isothermal conditions, in which the system was cooled at a constant rate (0.1, 1,10, or $100^{\circ} \mathrm{C} / \mathrm{s}$ ).

\section{Results and Discussion}

The finite-difference routine calculates the composition of ferrite and austenite as a finction of distance and time. The location of the ferrite interface is also determined so that the ferrite growth (or dissolution) can be readily followed as a function of time as well. Figure 3 shows a piot of the composition profiles as a function of distance for selected isothermal aging times at $1000^{\circ} \mathrm{C}$ for the $\mathrm{Fe}-21.9 \mathrm{Cr}-10.35 \mathrm{Ni}$ alloy. The calculations show that the ferrite grows slightly while becoming slightly leaner in chromium and richer in nickel. Under these conditions the austenite composition changes only sightly. The ferrite size can be readily converted into a ferrite content. The change in ferrite content can be followed more easily by considering it as a function of aging time, as is done in Figure 4 for both alloys. The resuits for aging at 1000 and $1200^{\circ} \mathrm{C}$ are shown in Figures $4(a)$ and (b), respectively. Similarty, the average chromium and nickel compositions of ferrite and austenite as a function of aging time at
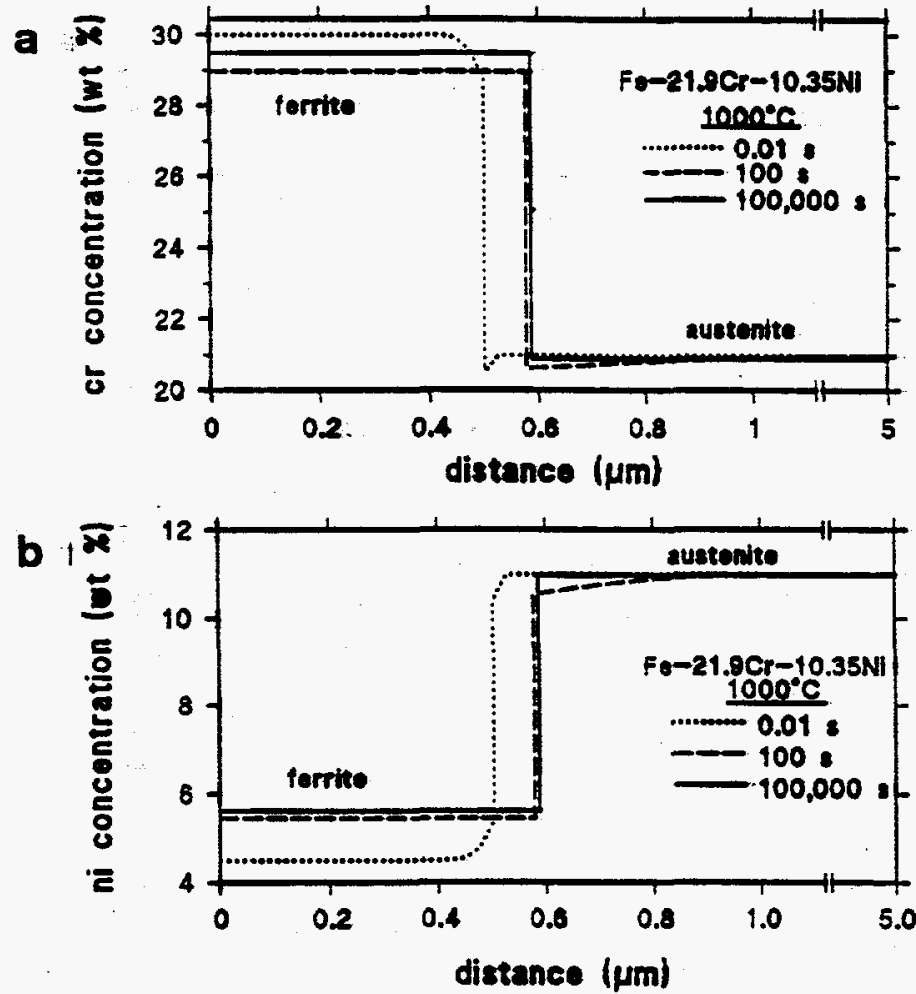

Fig. 3 - Typical calculated composition profiles for (a) chromium and $(b)$ nickel after aging at $1000^{\circ} \mathrm{C}$ for selected times. 
1000 and $1200^{\circ} \mathrm{C}$ are shoun in Figures 5 and 6.

Severat interesting features are found in Figures 4 through 6. First, for one alloy (Fe-21 Cr-11.3Ni), aging at $1000^{\circ} \mathrm{C}$ results in the total dissolution of the ferrite, yielding a fully austenitic structure [see Figure 4(a)]. For computational reasons, less than $0.2 \%$ ferrite was designated as "totally dissolved." Thus, the modet precticts-thesiging timer required for complete homogenization and elimimation of any residual ferrite. At $1200^{\circ} \mathrm{C}$, the ferrite remain stable in this alloy. For the other alloy, the ferrite remains s ateble constiment at all temperatures. In fact, at $1200^{\circ} \mathrm{C}$, for both alloys, ferrite growth is observed. For the Fe-21.9Cr-10.35Ni alloy, the ferrite content increases to nearly $35 \%$, and this growth is completed in less than 10,000 s. Even within $10 \mathrm{~s}$, which is comperable to the exposure time of the HAZ during multipass welding the ferrite content increases to more than $20 \%$. At $1300 \% \mathrm{C}$, the binetice are faster and the final amount of ferrite is ever greater (7). These results indicate that the HAZ undergoes substantial microstructural changes during multipass welding, and these changes are likely to have an impact on the solidification behavior, final microstructure, and properties.

The figures also show that the approach to final equilibrium is often not direct. For exampie, for the Fe-21.9Cr$10.35 \mathrm{Ni}$ alloy at $1000^{\circ} \mathrm{C}$, the ferrite chromium level initially decreases with aging, but with additional aging time, the chromium level recovers somewhat. This behavior was found under other conditions as well (7). It can also been seen that the change in ferrite content proceeds in two stages, as shown in Figure 4(b) for the Fe-21.9Cr-10.35Ni alloy. At other aging temperatures, it was

a

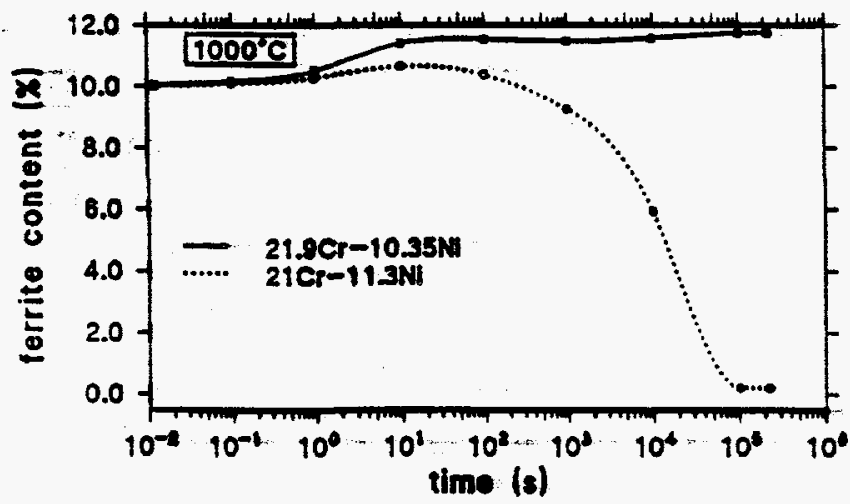

b

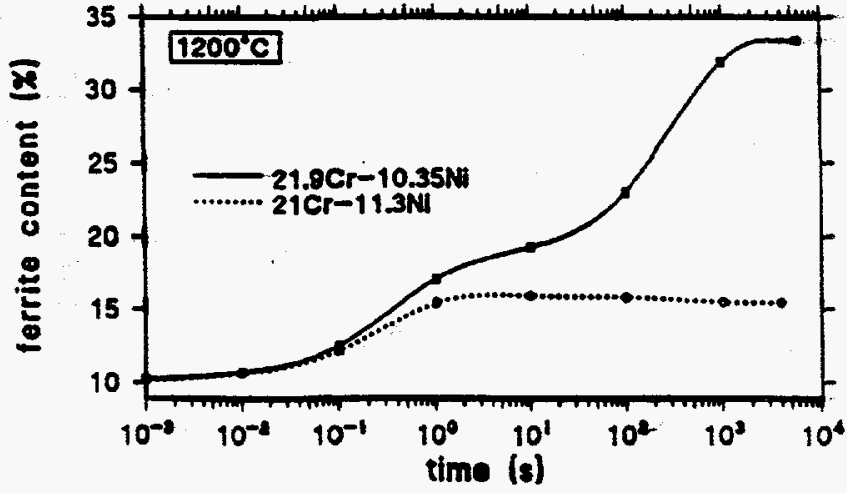

Fig: 4 - Calculated ferrite content versus aging time at (a) $1000^{\circ} \mathrm{C}$ and (b) $1200^{\circ} \mathrm{C}$. a

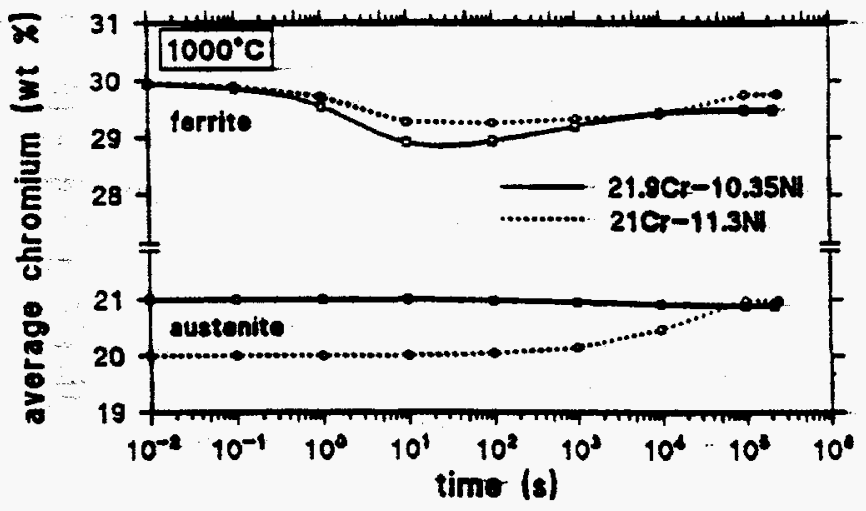

b

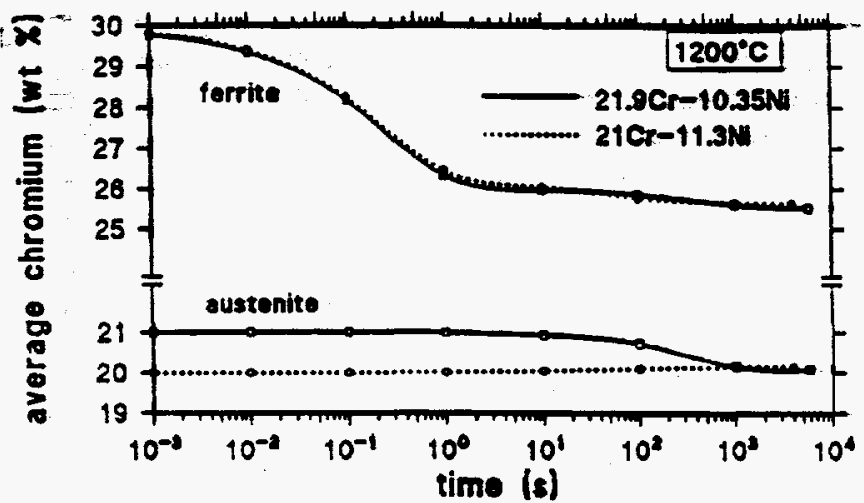

Fig. 5 - Average chromium compositions of ferrite and austenite as a function of aging time at $(a) 1000^{\circ} \mathrm{C}$ and $(b) 1200^{\circ} \mathrm{C}$.

a

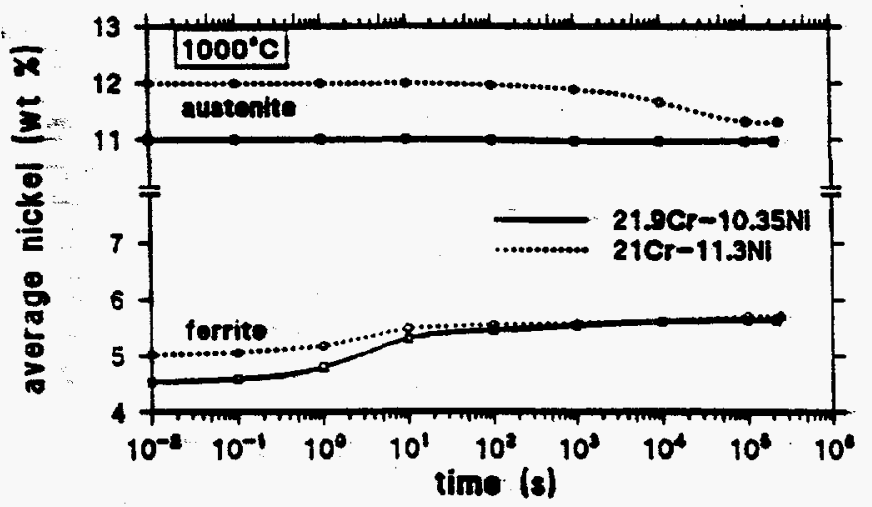

b

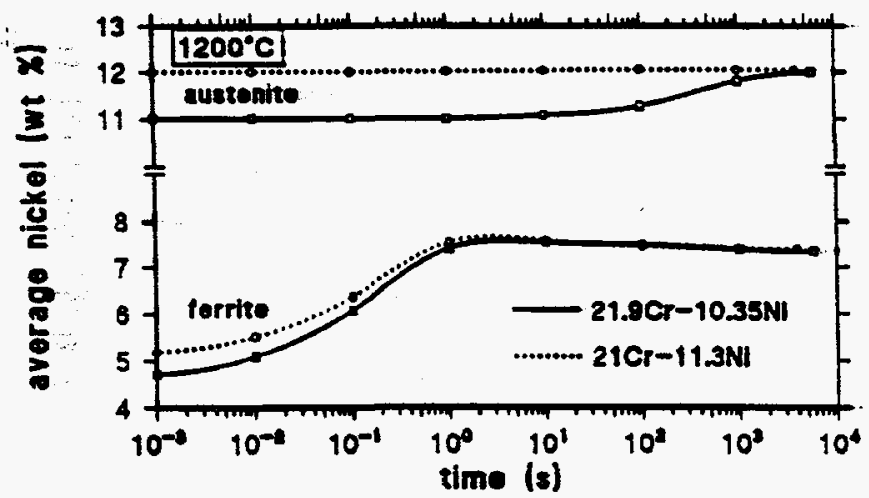

Fig. 6 - Average nickel compositions of ferrite and austenite as a function of aging time at (a) $1000^{\circ} \mathrm{C}$ and (b) $1200^{\circ} \mathrm{C}$. 
found that the ferrite content may increase before eventually decreasing; or vice versa $(4,7,16)$. These indirect paths toward finsl equitibrium were investigated further, and it was determined that the effects were real, these were not artifiacts of the calculation procedure. They arise from the condition of equilibrium at the interface and the required balance of chromium and nickel fluxes at the interface to yield ecomidtent value for the instantaneous growth rate of ferrite $(4,7,16)$. Generally speaking, the behavior at earty times is controlled by the ferrite diffusion, which is nearty two orders of magnitude greute then the diffusion in the austenite. At later times, the austenite diffision controls the equilibration process. Due to the nature of ternary and higher component systems, the tie line-that relates the ferrite and austenite compositions in equitibrium the interface is not fixed. Thus, the equilibrium interface compositions may, and do, change as a finction of time As a consequence, the fluxces at the interface also change, and this may resuit in irregular behavior such as ferrite growth initially, followed by ferrite dissolution. The reversal from growth to dissolution has been observed experimentally in austenitic stainless steel diffusion couples (10). Similariy, the change in tie-line compositions can also lead to reversals in the ferrite or austenite compositions as a function of time. This behavior is examined in more detail elsewhere (7).

Calculations were also made for non-isothermal heat treatments in which different constant cooling rates were utilized to simulate the cooling of the HAZ during weiding. These calculations were performed for the Fe-21Cr-11.3Ni alloy. The initial ferrite $(23.6 \mathrm{Cr}, 8.58 \mathrm{Ni})$ and austenite $(19.49 \mathrm{Cr}, 12.88 \mathrm{Ni})$ compositions, as well as the amount of ferrite (36.7\%), were adjested to represent approximately the compositions and amounts present in equilibrium at elevated temperatures $\left(1300^{\circ} \mathrm{C}\right)$. The ThermoCalc program was utilized to determine the hightemperature equilibrium state. The procedure calculated the composition profiles in the ferrite and austenite during cooling from 1300 to $700^{\circ} \mathrm{C}$, at a constant rate of $0.1,1,10$, or $100^{\circ} \mathrm{C} / \mathrm{s}$. The ferrite content, and ferrite and austenite compositions are plotted as a function of temperature in Figures 7 through 9, respectively. The equilibrium ferrite content and ferrite and austenite compositions as a fimction of teroperature are also shown in the figures (dashed lines are interpolations over temperanure ranges where the ferrite is not stable). The plots show that, in

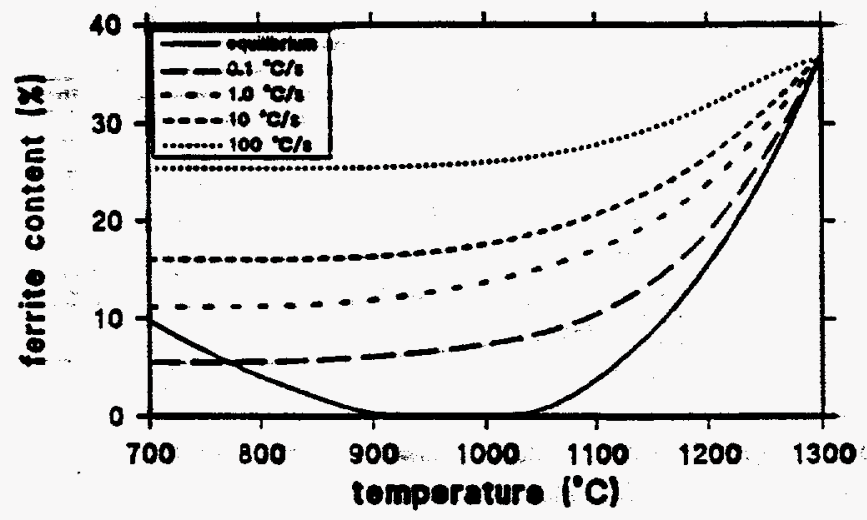

Fig. 7 - Calculated ferrite content versus temperature as a function of cooling rate from 1300 to $700^{\circ} \mathrm{C}$. general, as the cooling rate increases, the deviation from equilibrium increases as well. In addition, the curves show at what point the ferrite content, or phase compositions, no longer change appreciably with further cooling, in effect representing the temperature at which the mierostructure is effectively quenched. As is to be expected, at the higher cooling rates, the cormpositions or ferrite content are quenched-in more quickly. These curves can be used to determine the residual ferrite content and the phase compositions that are retained at room temperature as a function of those process conditions which affect the cooling rate, such as power, plate size, and welding speed.

A curious effect is found for the ferrite nickel content as a function of cooling rate [see Figure 8(b)]. Whercas at the highess cooling rate $\left(100^{\circ} \mathrm{C} / \mathrm{s}\right)$, the ferrite nickel content deviates almost inmodiately from the equilibrium value and remsins higher than the equilibrium compositions, the same is not true at the lower cooling rates In fact, in the range from 1000 to $1200^{\circ} \mathrm{C}$, the $10^{\circ} \mathrm{C} / \mathrm{s}$ condition actually has a ferrite nickel content that is cioser to equilibrium than that found at the lower cooling rates of 1 and $0.1^{\circ} \mathrm{C} / \mathrm{s}$. Furthermone, for the three lowest cooling rates, the ferrite nickel content is less than that found in equilibrium, indicating that the change in composition is actually greater than that for the equilibrium state. A more detailed examination of this behavior shows that it is a real effect that can be readily explained. As noted above, for some isothermal aging conditions, the ferrite nickel content may quickly decrease, initially, and then increase with additional aging time. This is, in fact, the situation for the Fe$21 \mathrm{Cr}-11.3 \mathrm{Ni}$ alloy at $1200^{\circ} \mathrm{C}$, when the starting compositions are
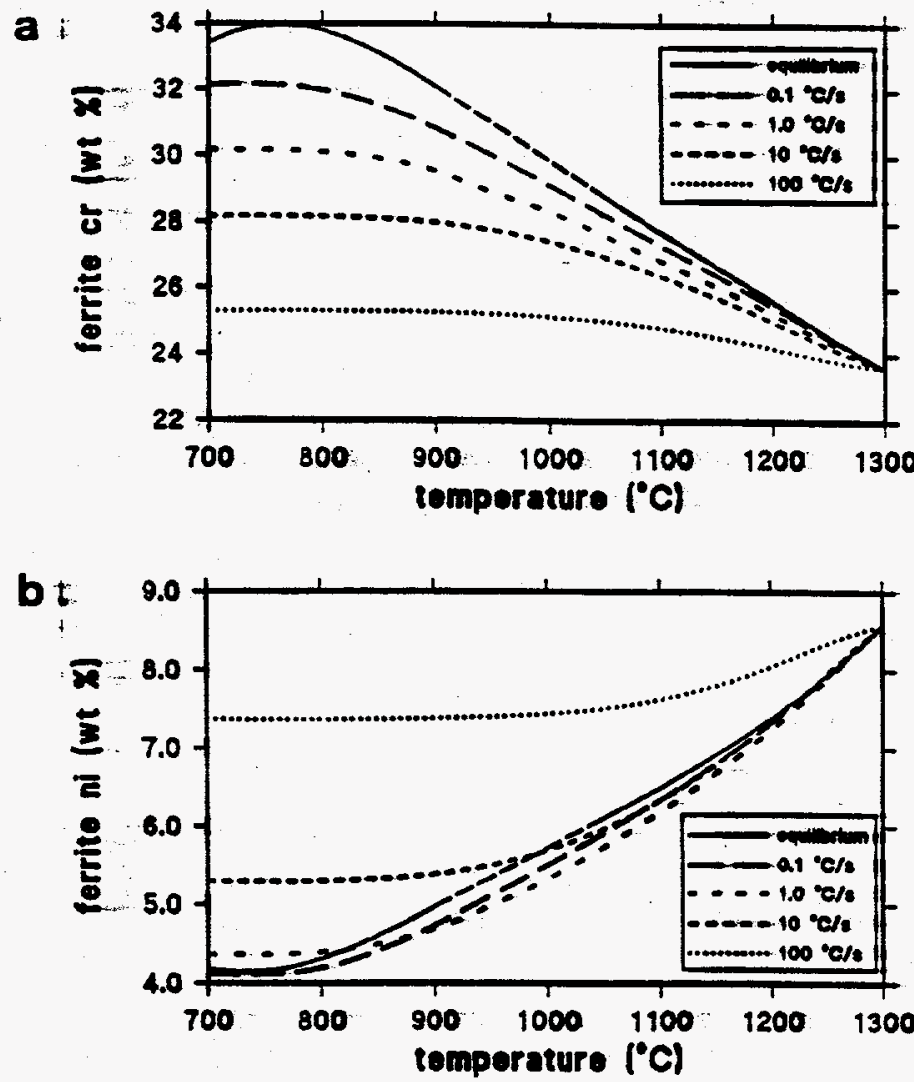

Fig. 8 - Ferrite (a) chromium and (b) nickel compositions as a function of temperature for different cooling rates. 
a

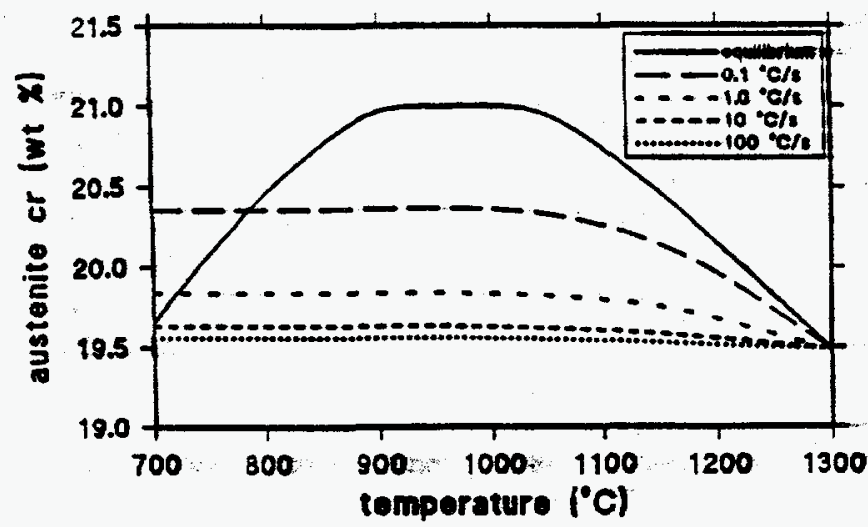

b

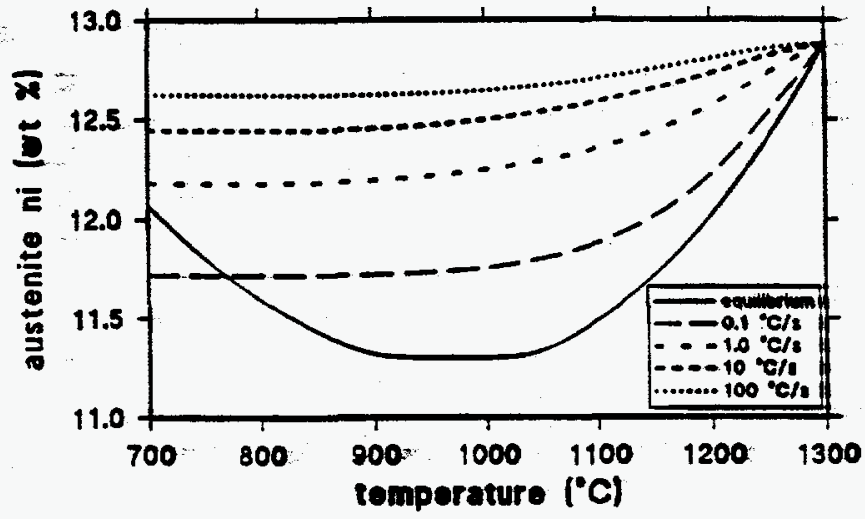

Fig. 9 - Austenite (a) chromium and (b) nickel compositions as a fimation of temperature for different cooling rates.

set at the equilibrium values at $1300^{\circ} \mathrm{C}$. The starting ferrite nickel content is $8.58 \%$, and the nickel concentration decreases quickly at first and then increases (4). During cooling at the slowest rates $\left(0.1\right.$ and $\left.1^{\circ} \mathrm{C} / \mathrm{s}\right)$, there is sufficient time for the ferrite nickel level to reach this minimum value, while at the $10^{\circ} \mathrm{C} / \mathrm{s}$ rate and higher, this minimum nickel level is not reached. Thus, the change in nickel content is less in the $10^{\circ} \mathrm{C} / \mathrm{s}$ case than for slower cooling rates, and this smaller change is actually closer to the final equilibrium nickel levei. It is noteworthy that this trend does not hold true for the chromium concentrations. Thus, the model calculations yield results that are understandable but not always intuitive. These findings suggest that model calculations are quite valuable, in that they can predict behavior that cannot be followed experimentally and would not be expected from simple intuitive arguments.

\section{Summary}

An implicit, finite-difference model has been developed and applied to study the diffusion-controlled ferrite-austenite transformation in austenitic stainiess steel welds. The model was applied to two Fe-Cr-Ni alloy compositions. The calculations provide valuable information on the microstructurat development in these steels as a function of thermal treatment. In particular, the conditions of isothermal aging at 700 to $1300^{\circ} \mathrm{C}$ and constant cooling from $1300^{\circ} \mathrm{C}$ were evaluated; and the quantities that were determined include ferrite content and average ferrite and austenite compositions. The model results also provide valuable infarmation on the kinetics of the transformation reactions: These quantitios are desirable to know because they play a major role in determining the weld properties and may also be influential in the solidification process. Furthermore, these quantities are often difficuit to measure experimentally, especiaily at the elevated temperatures to which the HAZ microstructures are exposed.

\section{Acknowledgments}

This research was spansored by the Division of Materials Sciences, U. S. Department of Energy, under contract DE-AC0584OR21400 with Lockheed Martin Energy Systems. The authors would also like to thank Y. S. Iskander for help with the calculations, and K. Spence, Dr. S. S. Babu, and Dr. M. K. Miller for their reviews of the paper.

\section{References}

1. Schaeffler, A. L., Metal Progr., 55(6), 680-680B (1949).

2. Kotecki, D. J. and T. A. Siewert, Weld. J., 71(5), 171s-178s (1992).

3. David, S. A., J. M. Vitek, and T. L. Hebble, Weld. J., 87(10), 289s-300s (1987).

4. Vitek, J. M. and S. A. Vitek, in Phase Transformations During the ThermainMechanical Processing of Steet, ed. E. B. Hawbolt and S. Yue, Canad. Institute of Mining, Metallurgy and Petroleum, Montreal, pp. $431-443$ (1995).

5. Tamilli, R A. and R. W. Heckel, Trans. Metall. Soc. AIME, 242, 2313-2321 (1968).

6. Randich, E. and J. I. Goldstein, Metall. Trans. A, 6A, 15531560 (1975).

7. Vitek, J. M., S. A. Vitek, and S. A. David, Metall. Trans. A, 26A, 2007-2025 (1995).

8. Murray, W. D. and F. Landis, Trans. ASME J. Heat Transfer; 81, 106-112 (1959).

9. Kaijhara, M., C. B. Im, and M. Kikuchi, in Stainless Steels 91. International Conference on Stainless Steels. Vol. 1 Iron and Steel Institute of Japan, Tokyo, pp. 677-684 (1991).

10. Kajihara, Masanori, Chang-Bim Lim, and Makoto Kikuchi, Iron Steel Inst. Jpn. Int., 33, 498-507 (1993).

11. Kajihara, M. and M. Kikuchi, Acta Metall Mater., 41, 2045 2059 (1993).

12. Sundman, B., B. Jansson, and J-O. Andersson, Calphad, 9, $153-190$ (1985).

13. Vitek, J. M. and S. A. David, Scanning Electron Microsc. 1981/, 169-175 (1981).

14. Vitek, J. M. and S. A. David, in Trends in Welding Research in the United States, ed. S. A. David, ASM, Materiais Park, Ohio, pp. 243-258 (1982).

15. Vitek, J. M. and S. A. David, Metall. Trans. A, 16A, 1521. 1523 (1985).

16. Vitek, J. M., S. A. Vitek, and S. A. David, in Solid $\rightarrow$ Solid Phase Transfomations ed. W. C. Johnson, J. M. Howe, D. E. Laughlin, and W. A. Soffa, The Minerals, Metals and Materials Society, Warrendale, Pa, pp. 201-206 (1994). 